\title{
REFLEXÕES SOBRE A ANÁLISE SISTÊMICA NA GEOGRAFIA TENDO O TEMA ÁGUA COMO REFERÊNCIA
}

\author{
Reflexiones sobre el análisis sistémico en geografía tomando el tema del agua como \\ referencia
}

\section{Camylla Silva Otto* \\ Eliana Marta Barbosa de Morais**}

\begin{abstract}
*Mestranda em Geografia na Universidade Federal de Goiás - camyllaottto@gmail.com
** Professora Dra. em Geografia na Universidade Federal de Goiás - elianamarta.ufg@gmail.com
\end{abstract}

Recebido em 20/10/2019. Aceito para publicação em 20/10/2019.

Versão online publicada em 10/11/2019 (http://seer.ufrgs.br/paraonde)

\begin{abstract}
Resumo:
No presente artigo buscamos evidenciar o atual aporte teórico-metodológico que tem encaminhado as pesquisas no interior da Geografia Física, relativas aos componentes físiconaturais do espaço geográfico, como o solo, as rochas, a rede hidrográfica, o relevo, dos quais destacamos a água, por ser um recurso essencial à vida. A ciência geográfica, tradicionalmente, desenvolveu seus estudos com base na análise de círculos concêntricos, sem considerar as dinâmicas, as diversidades, as contradições, fragmentando a relação entre sociedade e natureza. As novas exigências científicas, colocam em voga as lacunas que a ciência clássica apresentava, dessa forma, inicia-se na Geografia Física pesquisas pautadas na análise sistêmica, que busca analisar os componentes espaciais em sua integridade e dinamicidade. Consideramos a abordagem sistêmica um caminho válido para a abordagem da água, incluindo seu desdobramento no processo de ensino e aprendizagem na Geografia Escolar, visando a significação social desse conteúdo. Para subsidiar essa discussão, aportada pela metodologia de pesquisa qualitativa, realizamos revisão bibliográfica.
\end{abstract}

Palavras-chave: Geografia. Água. Análise Sistêmica.

\begin{abstract}
:
In the present article we seek to highlight the current theoretical-methodological support that has led the research within the Physical Geography, related to the physical-natural components of the geographical space, such as the soil, the rocks, the hydrographic network, the relief, of which we highlight water as an essential resource for life. Geographic science has traditionally developed its studies based on the analysis of concentric circles, without considering the dynamics, the diversity, the contradictions, fragmenting the relationship between society and nature. The new scientific demands put in vogue the gaps that classical science presented, thus begins in Physical Geography research based on systemic analysis, which seeks to analyze the spatial components in their integrity and dynamics. We consider the systemic approach a valid way to approach water, including its unfolding in the teaching and learning process in School Geography, aiming at the social significance of this content. To support this discussion, supported by the qualitative research methodology, we conducted a literature review.
\end{abstract}

Keywords:Geography. Water. Systemic Analysis. 


\section{Considerações iniciais}

A Geografia assim como qualquer outra ciência, não se consolida em seu surgimento. Ainda hoje, é possível compartilhar de reflexões acerca das "crises" no interior dessa ciência. Porém, não colocamos as mudanças de concepções teóricometodológicas como algo prejudicial à ciência, e sim como uma valorização às novas necessidades sociais, que se desdobram nos diversos campos, principalmente no técnico, científico e informacional. O meio técnico-científico-informacional para Santos (1994, p.70) é "[...] o momento histórico no qual a construção ou reconstrução do espaço se dará com um crescente conteúdo de ciência e de técnicas".

O objeto de análise da Geografia mudou ao longo do tempo, muito recente ela tem o espaço como seu objeto, assim, essa ciência se preocupa em estudá-lo, entendê-lo, compreendê-lo. Os componentes físico-naturais, estudados no interior da Geografia Física, fazem parte do espaço geográfico e devem ser estudados em sua dinamicidade, por isso, destacamos no presente texto, aportado na metodologia de pesquisa qualitativa, alguns referenciais teórico-metodológicos, como os de Bertalanffy (1973) e Gondolo (1999), que possibilitam prosseguir com essa referência na abordagem do componente água no Ensino de Geografia, por ser um elemento essencial à vida.

Nosso objetivo é que se rompa com o ensino tradicional de Geografia, caminhando para as reflexões que valorizam os processos e a dinamicidade dos componentes espaciais. O estudo da água não deve se pautar apenas em sua dinâmica interna, mas, para que se cumpra o objetivo da Geografia escolar, que se caracteriza pela percepção da singularidade, identidade e pertencimento dos estudantes no mundo (CALLAI, 2013), é necessário avançar para a dinâmica externa, aproximando o conteúdo da realidade social desses estudantes. Foi com o intuito de discutir essa proposição que apresentamos o presente texto.

Para isso, estruturamos o texto em três tópicos, sendo eles: Influências da perspectiva tradicional na Geografia; Reflexões iniciais sobre um ensino integrado do conteúdo água; A água como um componente integrador, e por fim, as considerações finais.

\section{Influências da perspectiva tradicional na Geografia}

Inicialmente, as ciências eram pautadas na identificação de regularidades dos fenômenos observáveis. Segundo Gondolo (1999, p. 57) "Havia a ilusão de poder reduzir o conjunto dos processos naturais a um pequeno número de leis imutáveis, regidas por matemáticas simples, acessíveis através dos meios finitos da mecânica racional".

Com o passar do tempo, novas necessidades surgiram, e as teorias e leis já formuladas, por si só, não conseguiam mais explicar os novos questionamentos científicos. As incertezas e as irregularidades dos fenômenos, que não se incluíam na ciência clássica, colocaram em pauta a necessidade de se avançar com as concepções teórico-metodológicas das ciências (GONDOLO, 1999).

Assim, em contraste com a concepção mecanicista das ciências, apareceram vários problemas de interação, de totalidade, necessitando ampliar as análises tradicionais para se chegar a reflexões complexas. Lacunas que também se destacaram

ParaOnde!?, Porto Alegre, v.12 n.2, p.271-280, 2019. http://seer.ufrgs.br/paraonde Edição Especial - III Colóquio de Pesquisadores em Geografia Física Ensino de Geografia 
na Geografia. Nesse sentido, Bertalanffy (1973) fala sobre as especializações da ciência moderna em virtude da complexidade das técnicas e estruturas teóricas, que se desdobram em inúmeras disciplinas em prol de se aprofundarem nos estudos e explicações teóricas. A esse respeito o autor enfatiza,

É necessário estudar não somente partes e processos isoladamente, mas também resolver os decisivos problemas encontrados na organização e na ordem que os unifica, resultante da interação dinâmica das partes, tornando o comportamento das partes diferentes quando estudado isoladamente e quando tratado no todo (BERTALANFFY, 1973, p. 53).

$\mathrm{Na}$ Geografia Física, vemos, diversas especializações, como a Pedologia, a Climatologia, a Geologia, a Geomorfologia, a Hidrologia e a Biogeografia. Sendo que, cada uma dessas, adquire cada vez mais subcampos. No interior da Geografia Física, buscamos desenvolver análises a respeito dos componentes físico-naturais do espaço, que são o solo, as rochas, a rede hidrográfica, o relevo, a vegetação, e desses, destacamos a componente água.

A água é um elemento primário para a existência e permanência da vida de qualquer espécie no planeta, por isso a preocupação de visualizar o seu encaminhamento na Geografia Física com vistas à uma abordagem significativa, pautada não na fragmentação, mas na interação entre todos os componentes físico-naturais do espaço. Contudo, não negamos a necessidade das especializações científicas, nem o estudo particular dos fenômenos, porém acreditamos que, o ensino de Geografia não deve se isolar nas dinâmicas internas dos fenômenos, mas caminhar para a compreensão das dinâmicas externas, que incluem o ser humano.

Bertalanffy (1973) conceitua o estudo dos fenômenos quando reduzidos à interação de unidades independentes umas das outras como sistemas fechados. No sistema fechado, subsidiado pela ciência clássica, busca-se identificar a previsão do comportamento de fenômenos a longo prazo, predizendo a evolução, em que as condições iniciais permitiriam caracterizar as condições finais, dessa forma, nega-se a dinamicidade dos componentes espaciais (GONDOLO, 1999). Contudo, novas reflexões teórico-metodológicas têm permeado a Geografia contemporânea, como a análise sistêmica, que visa um estudo integrado.

\section{Reflexões iniciais sobre um ensino integrado do conteúdo água}

Como um avanço teórico-metodológico nas ciências, que, atualmente, fundamentam os estudos dos componentes físico-naturais na Geografia Física são a análise sistêmica e o geossistema. Já na Geografia escolar, os fundamentos teóricometodológicos mobilizados para o ensino dos conteúdos baseiam-se nas teorias críticas, consolidadas, principalmente, no socioconstrutivismo (MORAIS, 2011).

A análise sistêmica difundiu-se, sobretudo, a partir da década de 1970 na Geografia Física. Dentre as teorias que adotam esse referencial, destaca-se a Teoria Geral dos Sistemas (TGS), criada pelo biólogo Ludwig Von Bertalanffy. A T. G. S. valoriza o sistema aberto em detrimento do sistema fechado. O sistema aberto é tido como uma teoria interdisciplinar, constituído, essencialmente, pelos organismos vivos, cuja condição é manter um contínuo fluxo de entrada e saída de energia, nunca estando em equilíbrio,

ParaOnde!?, Porto Alegre, v.12 n.2, p.271-280, 2019. http://seer.ufrgs.br/paraonde Edição Especial - III Colóquio de Pesquisadores em Geografia Física Ensino de Geografia 
mas podendo permanecer no estado estacionário (BERTALLANFY, 1973).

Lovelock (1979), criador da Teoria Gaia em que considera o planeta Terra como um grande organismo vivo, confirma que, em um mundo em completo equilibro seria impossível haver vida de qualquer espécie. Ao estudar a atmosfera terrestre e compará-la com a atmosfera de Marte e Vênus, o autor chega à conclusão que, a composição química da atmosfera alteraria completamente se todas as trocas de energia se esgotassem, aumentando o dióxido de carbono e anulando o oxigênio e o hidrogênio, e consequentemente alterando a composição química dos mares e oceanos. Segundo Debrun (1996 apud GONDOLO, 1999, p. 85) "esses resultados têm encurtado notavelmente o amplo fosso que existia entre matéria e vida".

O ciclo hidrológico só acontece devido as trocas de matéria e energia que são possibilitadas pelo movimento terrestre, pelo Sol e pela gravidade. Assim, para compreender a dinâmica hídrica, é conveniente considerá-la como um sistema aberto e não fechado, em que as trocas de matéria e energia ocorrem a todo tempo no planeta Terra, podendo passar pelo estado estacionário, mas não entrar em completo equilíbrio.

$\mathrm{Na}$ T. G. S. considera-se que os fenômenos observáveis possuem uniformidades estruturais, que se manifestam em diferentes campos, sendo esse o princípio unificador da teoria, constituindo-se como uma base para todas as ciências. Com isso, a teoria surge como uma solução à fragmentação das ciências, que objetiva formular modelos, princípios e leis universais que se aplicam a sistemas generalizados ou a subsistemas (BERTALLANFY, 1973).

A bacia hidrográfica é uma área superficial drenada por um rio principal. As bacias se diferem tridimensionalmente, em largura, altura e profundidade, por possuírem características próprias dos seus componentes físico-naturais, como vegetação, rede hidrográfica, solo, rochas, sociedade, entre outros. Mesmo não possuindo configurações idênticas, as bacias são regidas por uma lei geral, que é a gravidade. Como exemplo,

O escoamento superficial ocorre através da ação da gravidade gerada pelo desnível apresentado entre as cotas (encostas), a qual vence a força de atrito existente entre a água e a superfície do solo. A água escoa por caminhos preferenciais, favorecidos pelo relevo preexistente até atingir os cursos d'água, atuando como agente modelador do terreno através dos processos erosivos naturais (SCHIAVETTI; CAMARGO, 2002, p. 53).

Assim, a gravidade faz com que a água precipitada infiltre ou escoe superficialmente na bacia até a parte mais baixa do relevo, considerando também o processo de evaporação e evapotranspiração, em que a água não segue obrigatoriamente a declividade do terreno, retornado à atmosfera no decorrer do percurso.

O percurso da água, desde a precipitação ao curso de drenagem principal da bacia, atua como um agente modelador do relevo. Quanto mais acentuada for a inclinação do terreno maior o processo de erosão, que se aplica a toda e qualquer superfície terrestre, mas em algumas áreas o processo é estimulado e em outras não, devido ao tipo de clima e ao uso e ocupação do solo por exemplo, entre outros componentes físico-naturais de uma bacia.

As causa e efeitos da água em uma bacia hidrográfica podem ser estudadas por diversas disciplinas, principalmente pela Biologia e a Geografia. Mesmo o processo de distribuição da água numa bacia tendo uma característica específica e geral, que é a

ParaOnde!?, Porto Alegre, v.12 n.2, p.271-280, 2019. http://seer.ufrgs.br/paraonde Edição Especial - III Colóquio de Pesquisadores em Geografia Física Ensino de Geografia 
gravidade, cada ciência a estuda conforme os seus próprios interesses; a Biologia, por exemplo, pode se preocupar com a interferência que a inundação, de determinado lugar, tem sobre a fauna e a flora. Já a Geografia, pode preocupar-se com a influência da ocupação urbana sobre o abastecimento de aquíferos subterrâneos.

Nesse sentido, as correspondências entre os princípios que governam o comportamento é o mesmo - a gravidade determina que o percurso da água será das áreas altas para as áreas baixas, contudo, o interesse pelo estudo da influência do processo hídrico em uma bacia se altera de ciência para ciência, de pesquisador para pesquisador. Esses diferentes estudos científicos que podem partir de um mesmo princípio é segundo Bertalanffy (1968, p. 56) devido aos '"sistemas' ou complexos de elementos em interação", considerados sistemas abertos, em constante troca de matéria e energia.

Numa visão integrada dos componentes físico-naturais do espaço, Tricart (1977) no seu estudo da classificação econômica dos meios ambientes - ecodinâmica, faz uma correlação entre o solo, a precipitação pluviométrica e a vegetação, dizendo que no horizonte impermeável, o solo pouco expeço, confere um mau regime hídrico à camada superficial explorada pelas raízes. Assim, não há possibilidade de se desenvolver uma vegetação densa, como uma floresta, em solos com essas condições, que não permitem retenção da umidificação necessária à vegetação. E ainda introduz que, uma área de floresta e uma área de pastagem possuem papel hidrológico diferentes, enquanto a primeira capta com maior intensidade as águas das chuvas, na segunda há um acelerado escoamento da água.

Numa visão holística sobre o ensino da água, Bacci e Pataca (2008) sugerem que,

A educação para a água não pode, dessa forma, estar centrada apenas nos usos que fazemos dela, mas na visão de que a água é um bem que pertence a um sistema maior, integrado, que é um ciclo dinâmico sujeito às interferências humanas. Compreender a origem da água, o ciclo hidrológico, a dinâmica fluvial e o fenômeno das cheias, os aqüíferos, bem como os riscos geológicos associados aos processos naturais (assoreamento, enchentes) é essencial para que possamos entender a dinâmica da hidrosfera e suas relações com as demais esferas terrestres. Acreditamos que a água seja um tema de aproximação dos conhecimentos parcelares profundos e plurais e um tema que desenvolva a prática interdisciplinar (p. 217).

Assim, o princípio geral de uma análise sistêmica é uma visão integradora e dinâmica dos elementos que compõe o todo, formando uma unidade, dessa forma, os fenômenos que se manifestam no espaço podem se interagir, convergindo na manutenção do sistema, ou na alteração e modificação do mesmo. Morais (2011) destaca que, "os princípios básicos desta teoria têm sido aplicados em diferentes áreas do conhecimento, a exemplo do ecossistema na Biologia e do geossistema na Geografia" ( $p$. 256).

O geossistema foi desenvolvido pelo soviético Viktor Borisovich Sotchava na década de 1960. A proposta geossistêmica baseia-se na conexão entre natureza e sociedade, assim, está para além de estudar somente o "componente da natureza, mas as conexões entre eles; não se deve restringir à morfologia da paisagem e suas subdivisões, mas, de preferência, projetar-se para o estudo de sua dinâmica, estrutura funcional, conexões, etc" (SOTCHAVA, 1977, p. 2).

ParaOnde!?, Porto Alegre, v.12 n.2, p.271-280, 2019. http://seer.ufrgs.br/paraonde Edição Especial - III Colóquio de Pesquisadores em Geografia Física Ensino de Geografia 
Embora o autor considere os geossistemas como fenômenos essencialmente naturais, ao vislumbrar a contribuição geográfica na teoria dos sistemas, considerando a organização geográfica, que seria a distribuição dos componentes manifestados no espaço, inclui também, os fatores de ordem econômica e sociais como influenciadores estruturais e peculiares dos sistemas, e por isso da natureza. Pelo reconhecimento dessa contribuição geográfica à teoria dos sistemas é agregado o prefixo "geo" pelo referido autor.

Para Sotchava (1977) os Geossistemas "são uma classe peculiar de sistemas dinâmicos abertos e hierarquicamente organizados" (p. 9), mesmo se referindo a hierarquias, os geossistemas excluem a ideia de círculos concêntricos, valorizado na ciência clássica, cujas esferas não se interatuam, esses, são consideradas como sistemas fechados, com classificações próprias e independentes, como partes e processos isolados.

Assim, o autor considera que, os geossistemas possuem diferentes escalas, como a topológica, a regional, a planetária e as intermediárias (SOTCHAVA, 1977), identificando limites aos sistemas, níveis diferentes de organização, ao mesmo tempo em que possibilita as suas correlações, por isso a existência de sistemas dentro de sistemas, em que se definem com base em sua funcionalidade. Dessa forma, torna-se possível analisar a água em sua multiescalaridade, partindo da análise local à global.

\section{A água como um componente integrador}

Bertrand (2004) menciona que, no geossistema se encontram os elementos e combinações dialéticas mais interessantes para o estudo do geógrafo. Para ele, 0 potencial e a ocupação biológica dos sistemas são instáveis e variam no espaço e no tempo caracterizando diferentes estágios, representados pela paisagem, cuja evolução se dá por meio dos agentes naturais e agentes antrópicos.

Os elementos sociais, econômicos, tecnológicos, culturais, enfim, todos provenientes da ação humana, não são incluídos na origem dos sistemas, mas são tidos, apenas, como fatores que compõe a sua dinâmica. Para a teoria sistêmica, sempre o critério natural prevalece em detrimento do social, a sociedade surge como uma interferência no sentido essencialmente modificador e/ou transformador e não como participante da sua construção/formação.

Mather (1951, apudBertallanfy,1973) ao evidenciar uma das principais críticas à educação cita que, o mais importante não é a introdução de inúmeros conteúdo específicos ao longo de um ano ou um semestre em sala de aula, mas o encaminhamento de conceitos e princípios basilares que são válidos para todo o conhecimento. $O$ autor considera esses estudos integradores e totalizadores essenciais para a compreensão da realidade.

Às exigências educacionais de uma formação, considerando uma educação integrada que possui princípios básicos e interdisciplinares, são as que a T. G. S. procura satisfazer (BERTALLANFFY, 1973). Atualmente, o processo de ensino e aprendizagem é construído com base em alguns critérios, principalmente os de cunho político, desses, o Brasil segue os Parâmetros Curriculares Nacionais (PCNs), instituídos a partir da década de 1990. Os PCNs são utilizados como referência para a elaboração dos currículos das

ParaOnde!?, Porto Alegre, v.12 n.2, p.271-280, 2019. http://seer.ufrgs.br/paraonde Edição Especial - III Colóquio de Pesquisadores em Geografia Física Ensino de Geografia 
secretarias estaduais e municipais de educação de várias cidades e estados brasileiros.

Na Geografia escolar clássica, já se ensinava a água e a sua distribuição, como os maiores rios do mundo e os principais rios do país; mas a mobilização desses conhecimentos acontecia com base nos círculos concêntricos, ou sistemas fechados, o ensino era desconexo da realidade dos alunos e desprovido de uma análise integradora, que considerasse os processos. Contudo, reforçamos sim, a necessidade de se trabalhar a dinâmica interna dos elementos, saber quais são os maiores rios do mundo e do país, mas destacamos essencial trabalhar, também, a sua dinâmica externa.

Assim, por mais que haja limitações, elas não se esgotam com um bom planejamento e professores amparados nos conhecimentos didáticos do conteúdo, explicitados por Shulman (2005). Para estudar os componentes físico-naturais do espaço, como a água, destacamos a bacia hidrográfica como uma possibilidade temática. Pois a bacia hidrográfica poderá subsidiar um ensino dinâmico da água, considerando os demais elementos que influenciam em seus processos. Para saber qual é o maior rio do país ou do mundo, por exemplo, também devemos compreender quais os fatores que o possibilitou o ser; qual a influência histórica-social que tem à população; quais são os questionamentos político-administrativo que o envolvem; quais os usos e os cuidados ambientais que se têm realizado com esse curso de água; entre outros fatores que favorecem uma análise social do conteúdo.

Os alunos devem compreender o que é a água, de onde vem, para que serve, desde o seu surgimento à influência social que ela tem, se houver uma análise dinâmica e integradora desse elemento. Assim sendo, cumpriremos o objetivo desse ensino na Geografia, formar cidadãos conscientes, críticos e participativos socialmente.

Nesse sentido, Ab'saber (1969) ao analisar o encaminhamento das pesquisas Geomorfológicas, destaca que a Geomorfologia moderna não se preocupa em analisar os resultados cumulativos dos fenômenos físicos, mas a funcionalidade atual e integrada da paisagem. Nessa perspectiva, podemos considerar que a atuação da água em uma bacia hidrográfica, está sujeita a ação conjunta de todos os demais componentes físico-naturais da bacia. O autor enfatiza que,

Em muitos aspectos as observações sobre a epiderme da paisagem constituem modalidades de pesquisa, em grande parte aparentadas com as técnicas da geologia de superfície, através das quais observam fatos estáticos (cortes, afloramentos, solos superpostos), visando compreender a dinâmica do passado recente. No caso a situação é estática e pode ser estudada em qualquer tempo; a preocupação é a de entender uma paleo dinâmica a custa de fatos, todos dominantemente dedutivos. Enquanto que as pesquisas sobre a morfologia da paisagem são modalidades de pesquisa em situações efetivamente dinâmicas. Por isso mesmo pressupõe recursos técnicos, equipamentos locados, análises demoradas e observações de processos em plena atividade [...] (AB'SABER, 1969, p. 3-4).

O autor chama de morfologia da paisagem o estudo dinâmico e integrado dos componentes físico-naturais que atuam como formadores do relevo, como a hidrografia, a morfologia e a pedogênese, concordando assim com a teoria dos sistemas colocada por Bertalanffy (1973). Assim, atualmente, não basta somente caracterizar e descrever com exatidão os fenômenos hidrológicos, ou, estabelecer uma sequência do seu processo cíclico, é preciso também, considerar os aspectos não habituais, que advém principalmente da ação humana. Ao estudar o ciclo hidrológico, por exemplo, o autor

ParaOnde!?, Porto Alegre, v.12 n.2, p.271-280, 2019. http://seer.ufrgs.br/paraonde Edição Especial - III Colóquio de Pesquisadores em Geografia Física Ensino de Geografia 
introduz o termo hidrodinâmico, para se pensar a água em sua dinamicidade com o meio.

A Teoria Geral dos Sistemas não considera o ser humano como parte integrante dos elementos naturais/sistemas, mas um influenciador/modificador. Percebemos hoje que todos os lugares possuem interferência humana de forma direta ou indireta. Assim, concordamos com Morais (2011) ao colocar que,

[...] é necessário interpretar o relevo, o solo, as rochas, a hidrografia, a vegetação e o clima, além de identificar, localizar e classificar esses elementos e verificar em que medida eles, em seu conjunto, conformam a espacialidade de um lugar, o que constitui a singularidade de determinada área. Esses elementos têm significados diferentes de acordo com a valorização que a sociedade lhes atribui em cada contexto sociocultural (MORAIS, 2011, p. 259).

A Barragem do Ribeirão João Leite construída em Goiânia/GO, para alguns é apenas um lago que serve para o turismo, para outros é uma fonte financeira que gera lucros, para outros é apenas uma paisagem admirável, e assim sucessivamente, diferentes representações sociais existem para um mesmo elemento, dada as condições de valor de uso e valor de troca dos sujeitos. É preciso compreender o conjunto que está por detrás da aparência, com isso reforçamos a necessidade de se construir uma visão holística, integradora do elemento água, para que a sociedade amplie suas concepções teóricas utilizando-as praticamente em seu cotidiano.

\section{Considerações finais}

Vimos, no decorrer do texto, novas propostas teórico-metodológicas para encaminhar o ensino de Geografia. Estas, pautadas na análise sistêmica, em que se avança para o estudo integrado dos fenômenos, e não mais fragmentados, como na ciência clássica. No estudo dos sistemas fechados constatava-se princípios imutáveis de organização, na visão sistêmica compreendemos a interação dos elementos. Assim, ao encaminhar o ensino de água na Geografia Escolar o conteúdo estará próximo da realidade social dos estudantes, que passarão a não mais compreender o conteúdo pelo conteúdo, mas a importância social deste, contribuindo para uma efetiva prática cidadã.

Entendemos que, acontecimentos locais são manifestações globais que ocorrem diferentemente nas partes quando isoladas, podendo serem estimuladas ou não. Por isso a necessidade de se realizar análises multiescalares no ensino de água, sendo necessário compreender a dinâmica e os processos. A partir do conhecimento da dinâmica da água, numa visão integrada da bacia, das transformações e autoorganização, será possível caminhar para ações mais conscientes. Por exemplo, a falta de informação da população sobre a necessidade de preservar a qualidade da água e a falta de fiscalização contribuem para a continuação da degradação, se houver uma real conscientização haverá um investimento na difusão de informações, na comunicação para coordenar ações de preservação.

Algumas objeções são feitas por Bertalanffy (1973, p. 74) à Teoria Geral dos Sistemas: contrariamente ao método da ciência clássica, a T. G. S. não consiste na explicação ou aplicação de soluções exatas e conhecidas aos questionamentos que surgem, exigindo novas reflexões que engendrem noções de totalidade, de organização; perigo de analogias sem significações, como a superestimação ou subestimação de

ParaOnde!?, Porto Alegre, v.12 n.2, p.271-280, 2019. http://seer.ufrgs.br/paraonde Edição Especial - III Colóquio de Pesquisadores em Geografia Física Ensino de Geografia 
certos organismos em detrimento de outros, quando o que se pretende é a formulação e aplicação de modelos conceituais a fenômenos diferentes; por fim, considera que a T. G. S. não possui valor explicativo, mas, por se tratar de um campo complexo e em desenvolvimento, os estudiosos da teoria devem se "[...] contentar com uma com uma 'explicação em princípios', um raciocínio qualitativo [...]".

Assim, ressaltamos que a Teoria Geral dos Sistemas é um caminho teóricometodológico para a construção de um estudo integrado dos componentes físico-naturais do espaço. E que os professores, ao trabalharem a temática água na Geografia escolar, devem visualizar que, na Educação Básica não existe distinção entre Geografia Física e Geografia Humana, mas existe Geografia (MORAIS, 2011). Por isso, para que o ensino seja significativo, deve ser aproximado da realidade dos estudantes.

\section{Referências}

AB'SABER, A. N. Um conceito de Geomorfologia a serviço das pesquisas sobre o Quaternário. Geomorfologia, São Paulo, n. 18, 1969. p. 1-23.

BACCI, Denise de La Corte; PATACA, Ermelinda Moutinho. Educação para a água. Estudos Avançados 22 (63), 2008. p. 211-226.

BERTALANFFY L. O significado da Teoria Geral dos Sistemas. In: BERTALANFFY, L. $A$ teoria geral dos sistemas. Petrópolis: Vozes, 1973, p. 52-81.

BERTRAND G. Paisagem e geografia física global: esboço metodológico. R. RA'E GA, Curitiba, n. 8, 2004, p. 141-152.

CALLAI, Helena Copetti. A formação do profissional da Geografia: o professor. ljuí, RS: Ed. Unijuí, 2013. (Coleção ciências sociais). 186 p.

GONDOLO, G. C. F. Trabalhando com a complexidade. In: GONDOLO, G. C. F. Desafios de um sistema complexo à gestão ambiental. São Paulo: Annablume, 1999, p. 57-92.

LOVELOCK, J. O reconhecimento de GAIA. In: LOVELOCK J. Gaia - um novo olhar sobre a vida na Terra. Lisboa: Edições 70, 1979, p. 51-81.

MILTON, Santos. Técnica, espaço, tempo. Globalização e meio técnico-científicoinformacional. Hucitec: São Paulo, 1994.

MORAIS, Eliana Marta Barbosa de. O ensino das temáticas físico-naturais na geografia escolar. 2011. Tese (Doutorado em Geografia Humana) - Faculdade de Filosofia, Letras e Ciências Humanas, Universidade de São Paulo. São Paulo, SP, 2011. Disponível em: <http://www.teses.usp.br/teses/disponiveis/8/8136/tde-13062012-122111/.> Acesso em: 19 de julho, 2018.

SCHIAVETTI, Alexandre. CARMARGO, Antonio F. M. Conceitos de bacias hidrográficas: teorias e aplicações. Ilhéus/BA: Editus, 2002, 293 p.

ParaOnde!?, Porto Alegre, v.12 n.2, p.271-280, 2019. http://seer.ufrgs.br/paraonde Edição Especial - III Colóquio de Pesquisadores em Geografia Física Ensino de Geografia 
SHULMAN, L. S. Conocimiento y enseñanza: fundamentos de La nueva reforma. Profesorado. Revista de Currículum y Formación del Profesorado Granada-España, ano 9, n. 2, p. 1-30, 2005a. Disponível em: <https://www.ugr.es/ recfpro/rev92ART1.pdf> Acesso em: 19 de julho, 2018.

SOTCHAVA, V. B. O estudo de Geossistemas. Métodos em questão. IG-USP. São Paulo, n.16, 1977, p. 1-52.

TRICART J. Classificação ecodinamica dos meios ambientes. In: TRICART J. Ecodinânica. Rio de Janeiro: IBGE, 1977, p. 35-64. 